\title{
UNDERSTANDING BLOGGERS AND THEIR IMPACT FROM THE ASPECT OF SOCIAL ATTRACTIVENESS
}

\author{
Zehra Serman and Julian Sims \\ Birkbeck, University of London \\ Malet Street \\ London WC1E 7HX, United Kingdom
}

\begin{abstract}
This paper focuses on the impact of bloggers from the aspect of social attractiveness. It begins by giving an overview about bloggers and how widespread and powerful they have become since the advent of Web2.0. Next, it defines social attractiveness and its relation to bloggers. The paper highlights two important theories, Social Attention Holding Power (SAHP) and Status Derived Fighting Ability (RHS), to understand and analyse the ways consumers are influenced. The paper will define these theories and underline the features from the blogging perspective. Hence, it will define some strategies to gain success, discuss what was applied in psychology over the decades and will explain those strategies from blogging concept. It will give an overview of the looking glass effect and social comparison. Finally, the paper concludes by identifying a literature gap and need for further studies in this area.
\end{abstract}

\section{KEYWORDS}

Bloggers, Social Attractiveness, Social Attention Holding Power (SAHP), Status Derived Fighting Ability (RHP), Looking Glass Effect

\section{INTRODUCTION}

Bloggers have become a prevalent force in society today due to the emergence and growth of various social media platforms (Suh 2017). The influence of bloggers is increasing. This influence can be explained in various ways. Two step flow theory states that opinion leaders (bloggers) interpret media information they receive and pass it on to others (consumers). This flow mediates and increases the influence. This influence can be analysed by understanding the concept of 'social attractiveness'.

This paper evaluates blogging as digital marketing and bloggers as influencers that influence consumers' decision-making process. It highlights how bloggers are becoming widespread. Next, it gains insight into the question of how consumers are influenced and to understand the influence from the factor of social attractiveness through Social Attention Holding Power (SAHP) and Status Derived Fighting Ability (RHP) strategies (Figure 1).

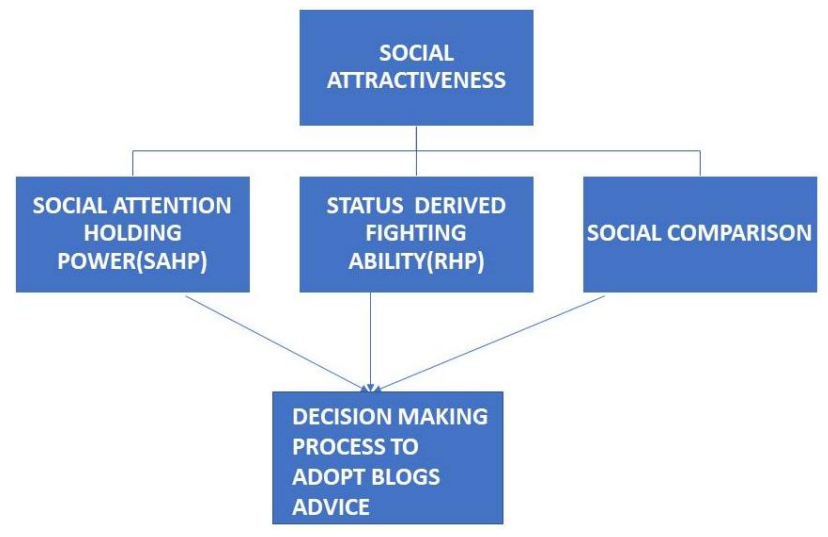

Figure 1. Conceptual Framework 


\section{BLOGGERS AND ITS IMPORTANCE}

The revolution of web based social platforms and rise in Web2.0 technology has led to blogging. Blogs consist of shared experiences, brief texts and posts and writers' recommendations. Writers who share their experiences and recommendations are bloggers. Some studies identify bloggers as opinion leaders because they are present in many sectors: fashion, health, beauty, tourism, food etc (Sokolova 2019). Studies indicate that 900,000 articles are published on blogs every day (Singer 2009); $55 \%$ of people review blogs more than ten times per day (Alsaleh 2017); 81\% of consumers read recommendations before purchasing a product (Wegert 2010): this high number was found in 2010, no doubt it has increased. Many readers and reviewers explains the power of bloggers and their influence on consumers. Bloggers who have a reputation are considered most credible and trustworthy. The reasons for this influence and ways of gaining status can be explained by understanding a factor 'social attractiveness', a concept borrowed from psychology.

\section{THE EVOLUTION OF SOCIAL ATTRACTIVENESS}

The capability of influencing others becomes very important as the number of bloggers and blog readers' dedication increases. Gilbert recognized social attractiveness as the most salient strategy to gain status and maintain success (Gilbert 1989) and argues that humans have innate need to be seen as attractive to others (Gilbert 1970). These needs moderate evaluations of social acceptance, social status and social bonds (Gilbert 1993). The loss of these needs' causes humiliation and shame. Social Attractiveness can be argued as the degree to which a person has ability to influence other people's state of mind and be socially accepted and approved by society. Positive social relationships are crucial for maintaining self and others happiness, therefore, social influence can be gained through cooperation and conformity (Leary 1995). Maintaining social bonds and conformity is not easy, especially when there are millions of bloggers in online platforms. Gilbert highlights the importance of social attractiveness and distinguishes the attracting display from threat of RHP, Gilbert (1989) called it "Social Attention Holding Power". Barkow suggests that status/prestige via attractiveness is an alternative form of status acquisition (Barkow 1980 and Kemper 1990).

\section{THE LOOKING GLASS EFFECT}

The increase in bloggers and their recommendations becomes very influential as blog readers are influenced in their choices and see them as role models. Gilbert states that many people with a balanced mind scarcely care about what others think of them, including who they are and what they do. In other words, we are image makers (Leary 1989). Pascal highlights that people are not limited with their lives only, but they desire to have an imaginary life in another state of mind, that's why people make an effort to prove themselves (Scheff 1988). Bloggers can be seen as part of this example. Their aim is to influence people and they desire to have an imaginary life in others. Hence, they try to build up reputation and recognition amongst blog readers. Habermas explains this situation as "self is a result of the social process whereby we learn to see ourselves as others see us" (Habermas 1987).

Moreover, Cooley defines the well-developed idea in sociology called looking glass effect, it is one way of understanding the influence of bloggers (Cooley 1902). Cooley argues that people are the result of imagination perceived in another's mind such as appearance, deeds, characters, friends. This imagined judgement forms an emotion Cooley introduces as "self-feeling". These in return influences actions. They are all diversely affected by it. This idea is familiar with the relationship between bloggers and blog readers. Bloggers are influencing consumers' decisions and those decisions cause a domino effect in other factors too. The ability to imagine one's appearance in a mirror can be understand by looking at blogger and blog readers' relationship. The self-reflection of what blog readers' and other bloggers will think about a specific blogger can be seen as a mirror effect. Blog readers have specific expectations or imagined appearances that they want to find or see in bloggers. This could be the way they interact with them or the way they dress or behave. The way they represent themselves. Therefore, Blog readers expectations and their imagined products or services determinates the mirror effect between blog readers' and bloggers. The mirror effect can also be seen between bloggers as they are competitors. Knowing that they are competitors, makes them imagine what others think 
or expect of themselves or how others judge themselves (Figure 2). This could potentially encourage them to do better or would cause worry, envy and depression leaving them scared of not being able to match the requirements of others' state of mind.

\section{SOCIAL ATTENTION HOLDING POWER AND BLOGGERS}

Gilbert suggests and that humans are more attracted to people when they feel they are valued by them. That person can be our friend, spouse, colleagues or the most influential blogger, its essential to pass on the positive attention and care in order to influence blog readers. Credibility forms the feeling of cared and valued. Hence Kemper suggests that, to be valued, chosen, admired and accepted, provides high status in others' minds (Kemper 1990). A credible person can be defined as qualified, experienced, trusted and have excellent communication skills. Esteban finds bloggers are more likely to gain status when they are credible and show positive attention communicating with blog readers. Gilbert identified strategies for gaining rank and success called "Social Attention Holding Power" (SHAP). This theory is composed of ability to elicit positive attention and social rewards such as approval, praise, acceptance, showing talent, respect, desire and admiration (Gilbert 1989). Showing talent and inspiring blog readers become challenging as the number of bloggers increases. However, it forms the essential basis of SAHP. Having talent with experience is very important. Blog readers take it seriously when bloggers are talented and experienced or have tried their recommended products. It also shows how much they value their readers. Bloggers who recommend make up products and are also talented in using those products, are considered more attractive than others. SAHP includes affiliative behaviours. An affiliative leader is the type of leader who develops harmony among people upon who they have influence. An affiliative leader tends to be connected to their followers and makes sure they can solve problems if questions or conflict occurs. People more likely to build up trust when there is an affiliation, positive attention from others, and instant communication and appreciation. Alsaleh (2017) studies the crucial importance of trust on consumers finding that trust positively influences blog readers intentions. Trust is vital and consumer behavior will only be influenced by bloggers when there is trust (Hsu et al., 2013).

Gilbert states that a lack of success in encouraging SAHP may result in negative outcomes. One of them is shame. Loss or damage of SAHP may lead to intense anger and fight. SAHP is a strategy to be accepted and gain socially approved from society. It forms social attractiveness. It explains one way of influencing others and how that influence occurs: showing talent, appreciation, positive attention is a way to influence other people's state of mind (Figure 3). Therefore, we can conclude that blog readers are influenced by bloggers who are socially attractive.

\section{STATUS DERIVED FIGTING ABILITY (RHP)}

Another way of influencing others is through showing fighting ability by undermining other people. This has been used for a very long time to demonstrate power and gain status over others. Many leaders and politicians had adopted this strategy to show overconfidence by fighting ability to influence others to become socially accepted.

Status derived fighting ability (RHP) is opposite to SAHP (Social Attention Holding Power). Signals of RHP are composed of threat, fighting ability, undermining others, showing authority over others. Baumeister (1989) suggests it is unattractive to be seen as weak and overly passive, which might not be an efficient way to influence others. Figure 4 below illustrates strategies for gaining rank and status adapted from Gilbert (1992)

RHP is the strategy whereby individuals evaluate themselves as superior to others (Price 1988). High self-esteem is one way of influencing others: people are more likely to be influenced by bloggers who have high self-esteem. This give them the impression that those bloggers are the experts in their domain. Believing their work and recommendations eventually builds up trust between them. Hence, it positively affects blog readers' intentions to purchase recommended products. Hutton and Baumeister points out that high self-esteem people grab attention by their abilities and talents where low esteem people are shame avoidant. 


\section{SOCIAL COMPARISON AND ITS IMPACT ON GAINING STATUS}

Social comparison is an efficient strategy to maintain or increase status (Gilbert 1992). Gilbert points out that comparing oneself with others enables one to estimate what other people will find attractive in others. This motivates us to perform specific tasks better to obtain favourable attention (Wolfe, Lennox and Cutler 1986). People invite an audience to compare with one or more others in different contexts such as giving musical performance or taking a job interview. In many domains of life, we are faced with situations where social comparisons take place (Gilbert 1992). As this occurs in all domains of life, this scenario must apply in the blogging context as well. The number of bloggers and posts are increasing every day and total numbers of blogs reached 440 million in 2019 (World Press 2019). Social comparison takes place between bloggers and between consumers to bloggers. There are bloggers who perform SAHP and are trying to influence consumers by giving positive attention and there are bloggers who show overconfidence and over self-esteem performing RHP. This paper suggests that the division of strategies becomes a mediating factor of social comparison. Bloggers who compare themselves with other successful bloggers tend to perform better and meet their followers' expectations. Those bloggers who make the comparison and are positively open to change are more likely adopting SAHP. However, there are also bloggers who are using RHP when influencing their blog readers. They are less likely to be involved in any comparison. Thus, they see themselves as best of all. Comparison would cause their self-esteem to break down. Hence, this becomes a mediator between two strategies to gain success and maintain it. Social comparison might occur in two ways. Bloggers to other bloggers might compare each other with their posts, the companies with which they work, the number of followers they have, numbers of comments or dislikes they get. This might encourage them to work harder or might cause jealousy and envy. It can be argued that, another type of social comparison takes place between consumers to bloggers. Blog readers' make comparison between bloggers. Blog readers care about bloggers attitude towards them. Bloggers who frequently post and communicate with them are considered valuable for blog readers. Bloggers who have talent and experience are more likely to persuade blog readers to adopt their recommendations. All these factors form social comparison between blog readers to bloggers. In case of a loss of prestige in any of these factors, it might cause bloggers to lose their followers and be faced with dislikes and unpleasant comments. It is challenging to turn other people's success into one's own opportunity by comparison. However, if that is achieved it could lead to success and social rank.

\section{LITERATURE GAP}

There have been various studies about bloggers: analysing types of bloggers or understanding how they became a prevalent force in marketing and consumer behaviour. However, very few studies analyse the reasons behind the influence on consumers. This study seeks to understand how status and social rank is gained over a community. Furthermore, existing literature does not shed light onto one of the most important factors: "culture". Culture is very important when analysing consumer attitudes and expectation. Thus, the influence of bloggers on consumers should be studied from a perspective of culture in further studies.

\section{CONCLUSION}

As bloggers have become popular in marketing products and services, it has created a huge influence over the attitudes and intentions of blog readers (consumers). How they gain success and social rank is discussed in this paper. To understand consumers, psychological theories and strategies have been applied in a blogging context. There are two principal ways to influence others: by passing positive attention to others; and by showing overconfidence and power. Both strategies appear to be practised, but it can be argued that SAHP with social comparison will increase success: it is essential to show confidence without undermining others. 


\section{REFERENCES}

Alsaleh, D (2017). Understanding the Role of Blogger Recommendations on Consumer Purchasing Behavior. The Journal of Business Inquiry 2017, 17, Issue 1 (Special Issue), 23-40.

Barrett, M., Oborn, E. and Orlikowski, W., 2016. Creating value in online communities: The sociomaterial configuring of strategy, platform, and stakeholder engagement. Information Systems Research, 27(4), pp.704-723.

Baumeister, R. F., Debra G. Hutton (1989, September). Self- Presentational Motivations and Personality Differences in Self-Esteeem. Journal of Personality, 57, pp.547-579.

Cooley, C.H. 1902. Human Nature and the Social Order (Revised edition). New York: Charles Scribner's Sons (1922).

Ebru Uzunoglu, S. M. (2014). Brand communication through digital influencers: Leveraging blogger engagement. Izmir: International Journal of Information Management 34.

Fishbein, M., \& Ajzen, I. Belief, attitude, intention and behavior: An introduction to theory and research. Reading, Mass.: Addison-Wesley, 1975.

Gilbert, P. (1997). The evolution of social attractiveness and its role in shame, humiliation, guilt and theraphy. British Journal of Medical Pyschology, 113-147.

Gilbert, P.,Price, J and Allan, S.(1995) Social Comparison, Social Attractiveness and Evolution: How Might They Be Related? New Ideas in Psychology, 13, 149-165.

Habermas, J. (1987) The Theory of Communicative Action, Vol.2, Polity Press, Cambridge.

Hernández-Méndez, J., Muñoz-Leiva, F. and Sánchez-Fernández, J., 2015. The influence of e-word-of-mouth on travel decision-making: consumer profiles. Current issues in tourism, 18(11), pp. 1001-1021.

Ho, C.H., Chiu, K.H., Chen, H. and Papazafeiropoulou, A., 2015. Can internet blogs be used as an effective advertising tool? The role of product blog type and brand awareness. Journal of Enterprise Information Management, 28(3), pp. 346-362.

Hsu, C.L., Chuan-Chuan Lin, J. and Chiang, H.S., 2013. The effects of blogger recommendations on customers' online shopping intentions. Internet Research, 23(1), pp.69-88.

Hwang, Y. and Jeong, S.H., 2016. "This is a sponsored blog post, but all opinions are my own": The effects of sponsorship disclosure on responses to sponsored blog posts. Computers in Human Behavior, 62, pp.528-535.

J.H.Barkow. (1982). A self-presentational view of social phenomena. Psychological Bulletin, 91, 3-312.

Lim, X.J., Cheah, J.H. and Wong, M.W., 2017. The Impact of Social Media Influencers on Purchase Intention and the

Mediation Effect of Customer Attitude. Asian Journal of Business Research, 7(2), p. 19.

Lu, L.C., Chang, W.P. and Chang, H.H., 2014. Consumer attitudes toward blogger's sponsored recommendations and purchase intention: The effect of sponsorship type, product type, and brand awareness. Computers in Human Behavior, 34, pp.258-266.

(O'Brien, 5th Edition 2011) Baltes, L.P., 2015. Content marketing-the fundamental tool of digital marketing. Bulletin of the Transilvania University of Brasov. Economic Sciences. Series V, 8(2), p. 111.

Paul Gilbert, J. P. (July 1995). Social Comparison, social attractiveness and evolution: How might they be related? New Ideas in Pyschology, Volume 13, Issue 2, Pages 149-165.

Patrutiu-Baltes, L., 2016. Inbound Marketing-the most important digital marketing strategy. Bulletin of the Transilvania University of Brasov. Economic Sciences. Series V, 9(2), p.61.

Ryan, D., 2016. Understanding digital marketing: marketing strategies for engaging the digital generation. Kogan Page Publishers.

Schafer, J. B. (2001). E- commerce Reccomandation Applications. Data Mining and Knowledge Discovery, 5 115-153.

Scheff, T.J. (1988). Shame and Conformity: The Deference- emotion system. American Sociciological Review, 53(3), 395406

Shrauger, J. S., \& Schoeneman, T. J. (1979). Symbolic interactionist view of self-concept: Through the looking glass darkly. Psychological Bulletin, 86(3), 549-573.

Sokolova, K and Kefi, H (2019) Instagram and YouTube bloggers promote it, why should I buy? How credibility and parasocial interaction influence purchase intentions, Journal of Retailing and Consumer Services.

Suh, A. 2017. Self-Branding on Social Media: An Analysis of Style Bloggers on Instagram. Procedia Computer Science, $124, \mathrm{pp} 12-20$

Wegert, T. (2010), Reach your customers while social media peaks. Retrieved January 31, 2014 from www.clickz.com/clickz/column/1699974/reach-your-customers-while-social- media-peaks

Wolfe, Raymond N.,Lennox, Richard D.,Cutler, Brian L.Journal of Personality and Social Psychology, Vol 50(2), Feb 1986. 